\title{
Video Article \\ The Hawaii Protocol for Scientific Monitoring of Coffee Berry Borer: a Model for Coffee Agroecosystems Worldwide
}

\author{
Melissa Anne Johnson ${ }^{1,2}$, Robert Hollingsworth ${ }^{2}$, Samuel Fortna ${ }^{2,3}$, Luis F. Aristizábal ${ }^{4}$, Nicholas C. Manoukis ${ }^{2}$ \\ ${ }^{1}$ Oak Ridge Institute for Science and Education \\ ${ }^{2}$ Daniel K. Inouye US Pacific Basin Agricultural Research Center, United States Department of Agriculture-Agricultural Research Service \\ ${ }^{3}$ College of Tropical Agriculture and Human Resources, University of Hawaii at Manoa \\ ${ }^{4}$ Independent Consultant on CBB Management
}

Correspondence to: Melissa Anne Johnson at melissa.johnson@ars.usda.gov

URL: https://www.jove.com/video/57204

DOI: doi: $10.3791 / 57204$

Keywords: Environmental Sciences, Issue 133, Agriculture, area-wide, Beauveria bassiana, crop infestation, electronic data collection, Hypothenemus hampei, integrated pest management, invasive insects

Date Published: 3/19/2018

Citation: Johnson, M.A., Hollingsworth, R., Fortna, S., Aristizábal, L.F., Manoukis, N.C. The Hawaii Protocol for Scientific Monitoring of Coffee Berry Borer: a Model for Coffee Agroecosystems Worldwide. J. Vis. Exp. (133), e57204, doi:10.3791/57204 (2018).

\section{Abstract}

Coffee berry borer (CBB) is the most devastating insect pest for coffee crops worldwide. We developed a scientific monitoring protocol that is aimed at capturing and quantifying the dynamics and impact of this invasive insect pest as well as the development of its host plant across a heterogeneous landscape. The cornerstone of this comprehensive monitoring system is timely georeferenced data collection on CBB movement, coffee berry infestation, mortality by the fungus Beauveria bassiana, and coffee plant phenology via a mobile electronic data recording application. This electronic data collection system allows field records to be georeferenced through built-in global positioning systems, and is backed by a network of weather stations and records of farm management practices. Comprehensive monitoring of CBB and host plant dynamics is an essential part of an area-wide project in Hawaii to aggregate landscape-level data for research to improve management practices. Coffee agroecosystems in other parts of the world that experience highly variable environmental and socioeconomic factors will also benefit from implementing this protocol, in that it will drive the development of customized integrated pest management (IPM) to manage CBB populations.

\section{Video Link}

The video component of this article can be found at https://www.jove.com/video/57204/

\section{Introduction}

Coffee Berry Borer (Hypothenemus hampei Ferrari) is an invasive insect pest that is found throughout major coffee growing regions of the world ${ }^{1,2}$. This tiny beetle spends most of its life cycle within the seed of a coffee berry, making it difficult to control with pesticide sprays. The adult female bores a hole into the coffee berry through the central disc, and into the seed where it builds galleries for reproduction. As the larvae develop, they feed on the endosperm, causing direct damage to the coffee bean and subsequent losses in yield and quality ${ }^{3}$. Indirect damage can also occur by the entry of fungi and pathogens into the bean, which can cause fermentation and alteration of the coffee flavor ${ }^{4}$.

CBB was first detected on Hawai'i Island in August $2010^{5}$ and quickly spread to nearly all of the $\sim 800$ coffee farms in the Kona and Ka'u districts, two areas that are world-renowned for the premium quality of their coffee products ${ }^{6,7}$. Unmanaged and poorly managed farms can have infestation levels in excess of $90 \%$, resulting in huge economic losses. In Hawaii, the estimated economy-wide impact due to CBB is approximately $\$ 21 \mathrm{M}$ annually ${ }^{8}$. CBB has continued to spread since its initial introduction to Hawaii Island, and was recently detected on the neighboring Hawaiian Islands Oahu (2014) and Maui (2016). Kauai is the only coffee-producing island in Hawaii that remains unaffected by CBB, but the island's 3,000 acres of coffee is extremely vulnerable to this highly dispersive pest.

Historically, synthetic insecticides such as endosulfan and chlorpyrifos have been used in many countries to control CBB. However, concerns regarding the toxicity of these insecticides to humans and the environment ${ }^{9}$, as well as evidence for insecticide resistance ${ }^{10}$, have resulted in these substances being banned from use in many countries. Currently, most coffee growing regions rely on an IPM approach to control CBB. IPMs typically involve a combination of sanitation practices (e.g., pruning and strip-picking), biological controls (e.g., the release of predatory beetles or parasitoids), and the application of biopesticides (e.g., the entomopathogenic fungus $B$. bassiana) ${ }^{11,12}$. Current recommendations for CBB management in Hawaii also suggest regular field monitoring using alcohol-baited traps and the "Thirty tree Sampling Method" developed by Cenicafé ${ }^{13,14}$. This sampling method involves randomly selecting a branch from the mid-canopy that has at least 45 green berries, and counting the number of infested and non-infested berries. This process is repeated in a zig-zag pattern across the field for a total of 30 trees per hectare (2.5 acres), and is used to estimate percent infestation.

While many of these IPM practices are being adopted by coffee growers in Hawaii, the extreme heterogeneity in climate, topography and cultural practices on the islands necessitate that IPM be customized to each location. The development of customized IPM will depend on a monitoring 
program that includes the essential elements of coffee agroecosystems, coffee pest biology, and the environment. We have implemented comprehensive monitoring of CBB and host plant dynamics as part of an area-wide project in Hawaii that aggregates landscape-level data to inform management practices. This protocol can be used in other coffee agroecosystems around the world, and will be especially useful in those that experience highly variable environmental and socioeconomic factors requiring customized IPM to manage CBB populations.

Protocol

Note: A Spanish translation of the protocol is provided as Supplementary File 1.

\section{Define Sampling Zones within Coffee Fields}

1. Survey the perimeter of the coffee field to be monitored using a global positioning system (GPS) instrument. Import the field coordinates into a global information system (GIS) and generate a map of the coffee field.

2. Divide the field into "zones" (i.e., polygons), each about $335 \mathrm{~m}^{2}$. These will be used to ensure a systematic random sampling design across the field.

\section{Create a Data Collection Application in an Electronic System}

1. Using an electronic data collection platform, build a data collection application comprised of the following interlinked databases: Traps, Zones, Site Service, Weather Stations, and Management.

Note: These databases will be used in all subsequent steps of the protocol for the collection and organization of data.

2. For the Traps database, create fields for 'site name', 'trap number', 'deployment date', 'field technician name', 'deployment photo', and a link to the GPS coordinates for each trap.

3. For the Zones database, create fields for 'site name' and 'zone number', with a link to the georeferenced site map displaying each zone.

4. For the Site Service database, create fields for 'site name', 'date', 'field technician name', and 'site notes'. Within the Site Service database create nested databases comprised of the following.

1. Include Trap Service to record trap number (with a link to relevant trap deployment record in the parent Traps database), photograph of trap catch, and trap count.

2. Include Zone Service to record phenology photographs, berry infestation assessment (total number of green berries, infested green berries, green berries with $B$. bassiana, and raisins), and a link to the relevant zone record in the parent Zones database; this record also includes GPS coordinates for each sampled tree.

3. Include Weather Station Service to record site name, date, data download, and battery check.

4. Include Berry Dissection to record lab technician name, date, and CBB position (AB or CD) and mortality category (alive, dead by other causes, or dead by Beauveria bassiana) for each dissected berry.

5. For the Weather Stations database, create fields for 'site name', 'station number', 'deployment date',' field technician name', 'deployment photo', and a link to the GPS coordinates for each weather station.

6. For the Management database, create fields for 'site name', 'date', and 'type of management practice'.

\section{Prepare and Deploy Traps for Monitoring CBB Movement}

1. Determine the number of traps needed to monitor CBB movement in each field. NOTE: Trap density per field should approximate 5 traps for small fields $\left(\sim 0.5\right.$ ha) and 10 traps for large fields $(\sim 1 \text { ha })^{15}$.

2. Using a thumbtack, make a series of drainage holes above the fill line in each trap collection cup to avoid dilution of the kill solution by rainwater. Assemble the funnel traps according to the manufacturer's instructions.

3. Prepare $1 \mathrm{~L}$ of kill solution comprised of $200 \mathrm{~mL}$ of propylene glycol and $800 \mathrm{~mL}$ of water. Next, prepare an attractant mixture comprised of a $3: 1$ solution of methanol:ethanol. Pour $40 \mathrm{~mL}$ of the attractant into plastic semi-permeable bags ( 2 mil, 3 inch $\times 4$ inch) and place in a container for transport.

NOTE: Semi-permeable bags have been shown to perform better than open vials in attracting CBB, and also require less frequent visits to refill lures due to lower elution rates ${ }^{16}$.

CAUTION: Methanol and ethanol are highly flammable liquids, are toxic if inhaled or ingested, and are skin and eye irritants. These chemicals should be handled in a well-ventilated room while wearing gloves, eye protection, and protective clothing.

4. Deploy the traps by randomly distributing them across the field. Place traps $0.5-1.5 \mathrm{~m}$ above the ground, and clear of the aisles. Stakes may be used to effectively secure traps between trees. Write the site name and trap number with permanent marker on each trap for future identification.

5. Fill trap collection cups with $100 \mathrm{~mL}$ of the glycol kill solution and screw the cups tightly into place. Attach a paper clip to each attractant bag and use the paper clip to hook the bag to the center of the trap.

6. Using a mobile device equipped with the electronic data collection platform, navigate to the Traps database and create a new deployment record comprised of the site, date, trap number, and a photograph of the trap.

NOTE: The location of the trap within each field is automatically recorded via GPS on the mobile device.

\section{Service Traps}

1. Upon arrival in the field, navigate to the Site Service database within the electronic system and create a new site service record comprised of the site name, date, and field technician name. 
NOTE: The initial trap service is conducted two weeks after trap deployment, and every two weeks thereafter. If higher-resolution trap catch data is desired, a weekly trap servicing may be done, although we note that bi-weekly sampling is sufficient to capture general movement trends throughout the season (Figure 1).

2. Locate the trap in the field. Place a fine-mesh hand sieve (mesh size $0.8-1.0 \mathrm{~mm}$ ) onto a plastic container and pour the kill solution from the collection cup through the sieve. Transfer the kill solution back to the collection cup and swish the liquid around to ensure that all the CBB are removed from the collection cup.

3. Within the new site service record, navigate to the Trap Service database and create a new trap service record. Enter the relevant trap number, and photograph the sieve with the site name and trap number in the background. Save the photograph to the trap service record.

4. Using a spoon or metal spatula, scoop all insects into a vial filled with $70 \%$ ethanol. Label the vial with site, date, and trap number.

5. Refill the collection cup with fresh kill solution and screw back onto the trap. Once per month wash out the collection cup with soapy water, rinse, and replace with fresh kill solution. Also replace the attractant and bag once per month or as needed.

\section{Service Zones for Plant Phenology}

1. Within the site service record, navigate to the Zone Service database and create a new zone service record. Select a sampling zone from the site map in the linked Zones database.

2. To avoid sampling bias, randomly select a tree from within the zone by casting eyes downward so only the bases of the trees are visible. Standing in front of the selected tree, randomly choose a lateral branch around chest height. Clip a ruler onto the selected branch, making sure that the ruler does not block any of the reproductive parts (nodes, buds, flowers, fruits) from the camera's field of view.

3. Take a single photo ensuring that the ruler and the entirety of the target branch are visible. Take a second photo of the whole tree; try to get as much of the mid-level canopy in the photo as possible. Save both phenology photos to the Zone Service record.

\section{Service Zones for Damage Assessments of Green Berries}

1. If the branch used for phenology appears to have $>30$ green berries, count the number of berries on the branch that are at least pea size $(\sim 0.6 \mathrm{~cm})$ and larger, and are green to light yellowish-green in color $\left(\mathrm{BBCH}\right.$ scale $\left.77-85^{17}\right)$. Enter this number into the Zone Service record. NOTE: If the branch used for phenology appears to have $<30$ green berries, haphazardly select a lateral branch at about chest height from a tree in the target zone with $>30$ green berries visible. Do this from a distance to avoid bias in selection.

2. Also in the Zone Service record, enter the number of green berries infested by CBB on the branch. Infested berries will have a small hole that is typically located in the central disc; CBB may or may not be visible in the hole.

3. Enter the number of green infested berries with visible white $B$. bassiana fungus. The fungus may be seen on the CBB and/or surrounding the entrance hole.

NOTE: Further assays may be needed to identify fungal species if this is of special interest.

4. Enter the number of raisins (dried berries) on the branch. This information can be used to understand relationships between management practices (e.g., strip picks) and CBB infestation.

5. Collect three infested green berries from the branch; these will be taken back to the lab and dissected to assess CBB position within the berry.

NOTE: Green infested berries may be acquired from other branches within the zone if the branch used for the damage assessment has $<3$ infested green berries.

6. Place infested green berries in a plastic container and label with the site and date. Store containers in a cooler on ice until they can be transported back to the lab.

Note: Ideally, berries should be dissected within 1 - 3 days of collection to ensure maximum survivorship of CBB.

1. Store berries (as needed) in the lab at $14{ }^{\circ} \mathrm{C}$ for up to three days with little to no mortality (S. Fortna \& R. Hollingsworth, personal communication).

7. Repeat steps for phenology and berry damage assessments in each sampling zone. NOTE: Approximately 25 branches should be sampled for large farms $(\sim 1$ ha), and $\sim 15$ branches should be sampled for small farms $(\sim 0.5$ ha). For dissections, 75 green infested berries should be collected from large farms, and 45 from small farms on each sampling date. During some parts of the year, it may not be possible to collect this number of berries. In this case, try to collect a minimum of 50 green berries for large farms ( $1 \mathrm{ha})$ and 30 green berries for small farms ( $0.5 \mathrm{ha})$.

\section{Count the Number of CBB in Each Trap}

1. Place a coarse-mesh hand sieve (mesh size $\sim 1.5 \mathrm{~mm}$ ) over a plastic container, and empty the beetles from the collection vial into the sieve. Use a wash bottle filled with water to get all the contents out of the vial.

2. Use the wash bottle to spray the contents in the sieve, forcing as many small insects through the sieve as possible. This permits larger insects and debris to be separated out from the small beetles in the sample, and limits inaccuracies in volumetric estimates of CBB. Discard the large insects and debris and rinse out the sieve.

3. Place a fine-mesh hand sieve (mesh size $\sim 1.0 \mathrm{~mm}$ ) over a second plastic container, and pour the contents of the first container into the finemesh hand sieve.

4. If there are more than several hundred CBB, skip ahead to step 7.6. If there are less than several hundred CBB, place the fine-mesh sieve onto a paper towel to remove excess water. Turn the sieve upside down and tap all the contents onto a clear plastic lid. Spread the beetles around with a paintbrush if they are clumped together, and allow them to sit until dry.

5. If there are less than several hundred $\mathrm{CBB}$, use a fine-tipped paintbrush or similar implement to line the beetles up into rows that are several beetles wide, and begin counting under a light microscope. Count the total number of beetles and separate into "CBB" and "other" categories.

6. If there are more than several hundred CBB, transfer the CBB from the fine-mesh sieve to a 10-mL syringe using a metal spatula. Place the ejector column into the syringe and press downward gently until a slight resistance is felt, while being careful not to crush the beetles. Record the volumetric value on the syringe. 
7. Count 200 beetles from the volumetric sample using the protocol described above. Use the following equations to determine the number of CBB versus other beetles in the sample.

1. Estimate CBB count using:

Total CBB estimate for the sample $=(\# \mathrm{CBB} \div 200) \times \partial \times(\mathrm{mL}$ measured in syringe $)$.

NOTE: Here $\partial=$ the number of insects $/ \mathrm{mL}$. It is recommended that an estimate of $\partial$ be made for each region; on Hawaii Island a value of 1033 was measured.

2. Estimate other count using:

Total "other" beetle estimate for the sample $=(\#$ Other $\div 200) \times \partial \times(\mathrm{mL}$ measured in syringe $)$.

8. When the trap count has been completed, navigate to the relevant Trap Service record and enter the number of CBB and other beetles.

\section{Score Phenology Photographs}

1. Export the coffee phenology photographs from the data collection application. Open the photograph and locate the branch with the attached ruler. For this branch score the following.

1. Score the number of nodes (attachment points of the leaves to the branch).

2. Score the presence or absence of immature buds, mature buds, candles, open flowers, and pin heads.

3. Score the number of pea sized green berries, immature green berries, mature green berries, berries showing a color break, fully ripe berries, and raisins.

\section{Dissect Berries to Determine CBB Position}

1. Take the infested green berries out of cold storage and allow them to warm to room temperature for 10-15 min before proceeding with berry dissection. This recovery time is important so that CBB can be accurately assessed as alive or dead.

Note: Dissection of the infested berries allows the position of adult CBB to be determined. Position AB indicates the female has initiated penetration into the berry but has not reached the endosperm; position CD indicates the female has entered the endosperm ${ }^{13}$.

2. Using a scalpel or similar implement, make a slice through the berry parallel to the central disc as a preliminary assessment of beetle position. Next, make a series of shallow slices perpendicular to the central disc and around the entrance hole to determine if the CBB is in the $\mathrm{AB}$ or $\mathrm{CD}$ position.

3. Subdivide the AB and CD categories into "alive", "dead by Beauveria bassiana", "dead by other causes", and "beetle missing". If it is unclear if the adults are alive or dead, zoom in with the microscope and watch the legs for movement.

4. Place counted individuals into a dish with water or alcohol. This helps to keep track of what has been counted, and prevents adult beetles from escaping into the lab.

5. Once the dissections for a site are completed, navigate to the Berry Dissection database in the relevant site service record and enter the total number of CBB in each category.

6. Place dissected samples in a container and freeze for $72 \mathrm{~h}$ before disposal.

\section{Service Manual Weather Stations}

Note: Weather stations requiring manual data download may be serviced bi-weekly or monthly to download data and ensure all sensors are working properly. Weather variables that are important to consider for understanding CBB biology may include rainfall, humidity, air and soil temperature, solar radiation, photosynthetically active radiation (PAR), soil moisture, and wind speed/direction.

1. Locate manual weather stations in the field. In the electronic system, open the relevant Site Service record and navigate to the Weather Station Service database. Create a new weather station servicing record that is linked to the relevant weather station deployment record.

2. Use a waterproof shuttle to directly connect the data logger and laptop for data download. Make a note in the weather station servicing record that data was downloaded.

3. Once data has been off-loaded, manually re-launch the solar and temperature/humidity loggers to ensure they have the correct settings (rainfall logger does not need to be re-launched). Check battery level and replace as needed. Make a note in the electronic system that this has been done.

4. After returning to the lab, add the most recent data to the full weather stitches and update the metadata record.

\section{Record Management Practices}

NOTE: Information on management practices may be used to understand patterns in CBB activity and population sizes. Relevant management practices may include (but are not limited to): spraying $B$. bassiana fungus, spraying pyrethins or other insecticides, pruning, weed management, strip picking, cherry picking, removing raisins from the ground, etc.

1. In the Management database, create a new management record with the site name, date and type of management practice conducted. 


\section{Representative Results}

We report examples from several coffee farms that are representative of the type of results that may be obtained from the monitoring protocol described above. To determine CBB movement patterns within and among fields, the total catch for a given trap may be divided by the number of days since deployment to estimate the number of CBB caught per day. The number of CBB caught per day may then be averaged across all traps to determine the mean number of CBB caught per trap per day across the farm (mean \pm SEM; Figure 2). Trap catch data may be used to infer periods of peak flight activity ${ }^{18}$, and can also be used to direct management activities such as pruning and $B$. bassiana sprays. Percent infestation obtained from berry damage assessments in the field may be compared with trap catch data to determine if periods of high infestation coincide with peak flight activity ${ }^{19}$. This information is essential for deciding if monitoring CBB activity through traps alone is sufficient to inform control measures. Berry dissections in the laboratory to determine CBB positions may be used to inform growers when to spray applications of $B$. bassiana ( $>5 \%$ of $\mathrm{CBB}$ are in the $\mathrm{AB}$ position ${ }^{14}$ ). CBB position information can also be used in conjunction with hotspot maps generated from damage assessments in the field to inform growers of approximate locations within the field where $B$. bassiana should be sprayed (Figure 3 ).

A comprehensive view of the factors involved in CBB infestation may be obtained by compiling data on CBB positions, mortality by $B$. bassiana, plant phenology, and management practices. In the sample farm shown in Figure 4, the majority of infested berries dissected early in the growing season hosted CBB in the AB position, while the majority of berries dissected later in the season hosted CBB in the CD position. Following a peak in berry production, seven rounds of cherry harvesting were recorded from late July to December (Figure 4). Finally, seven applications of $B$. bassiana were conducted at approximately one month intervals throughout the season, with CBB mortality observed to range from $0-23 \%$ (Figure 4). Lastly, although weather data is not presented here, the addition of temperature, humidity, and rainfall information will likely provide further insights into factors driving CBB infestation patterns and $B$. bassiana effectiveness on coffee farms.

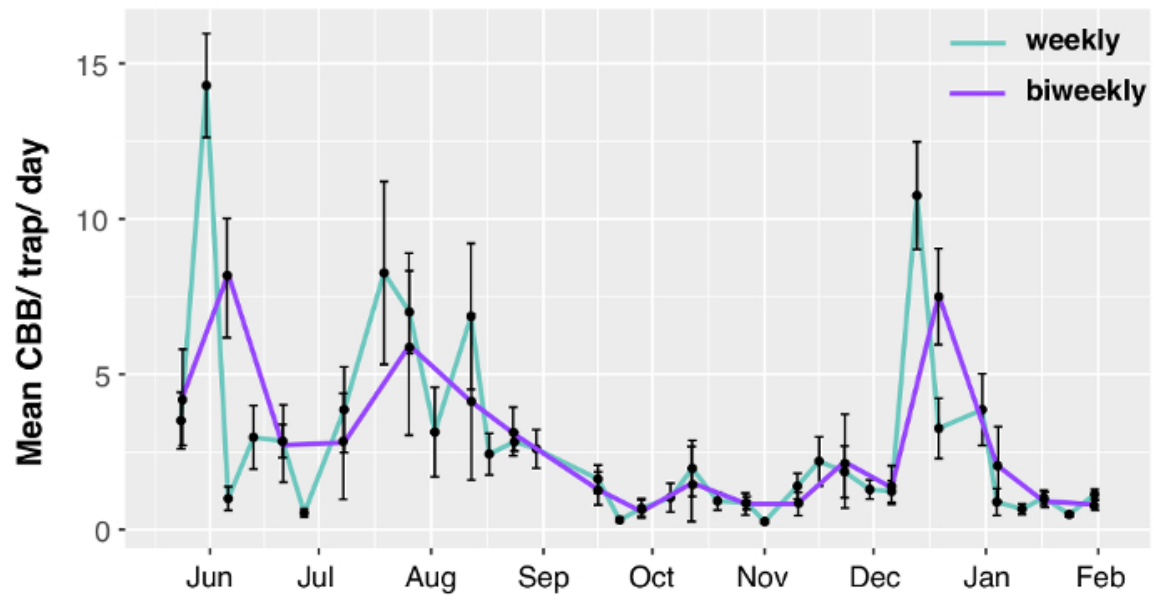

Figure 1. Mean ( \pm SEM) CBB caught per trap per day for sampling done at weekly versus bi-weekly intervals. This average trap catch per day is for five funnel traps spread randomly across the farm. More extreme peaks and troughs are captured in the weekly sampling and these peaks appear slightly later in the bi-weekly sampling, although the general trends are comparable between the two intervals. Please click here to view a larger version of this figure.

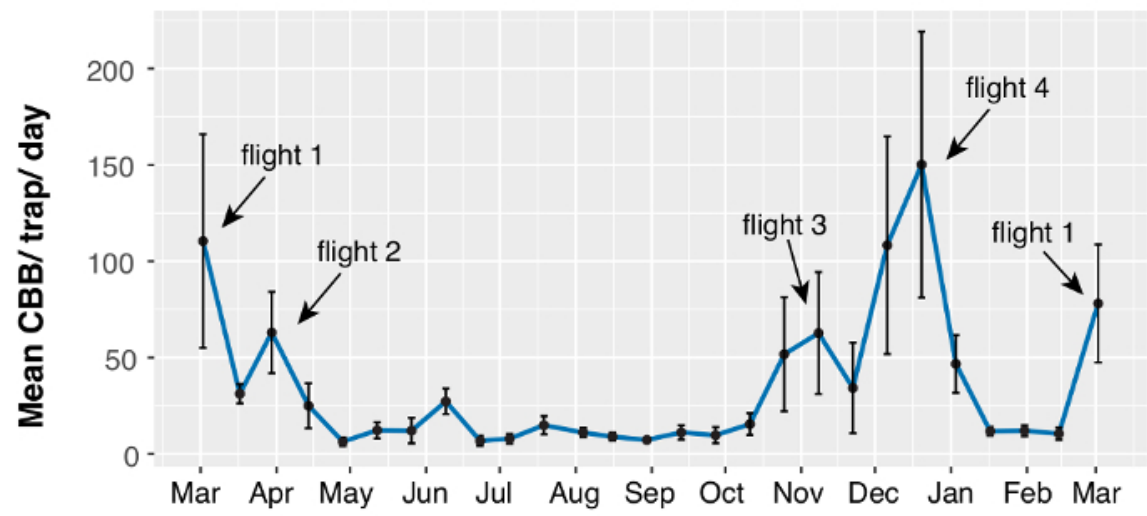

Figure 2. Mean ( \pm SEM) CBB caught per trap per day. This average trap catch per day is for nine funnel traps spread randomly across the farm. Two major peaks in CBB flight activity can be seen at this farm (March and December) during the 2016-2017 growing season. Please click here to view a larger version of this figure. 


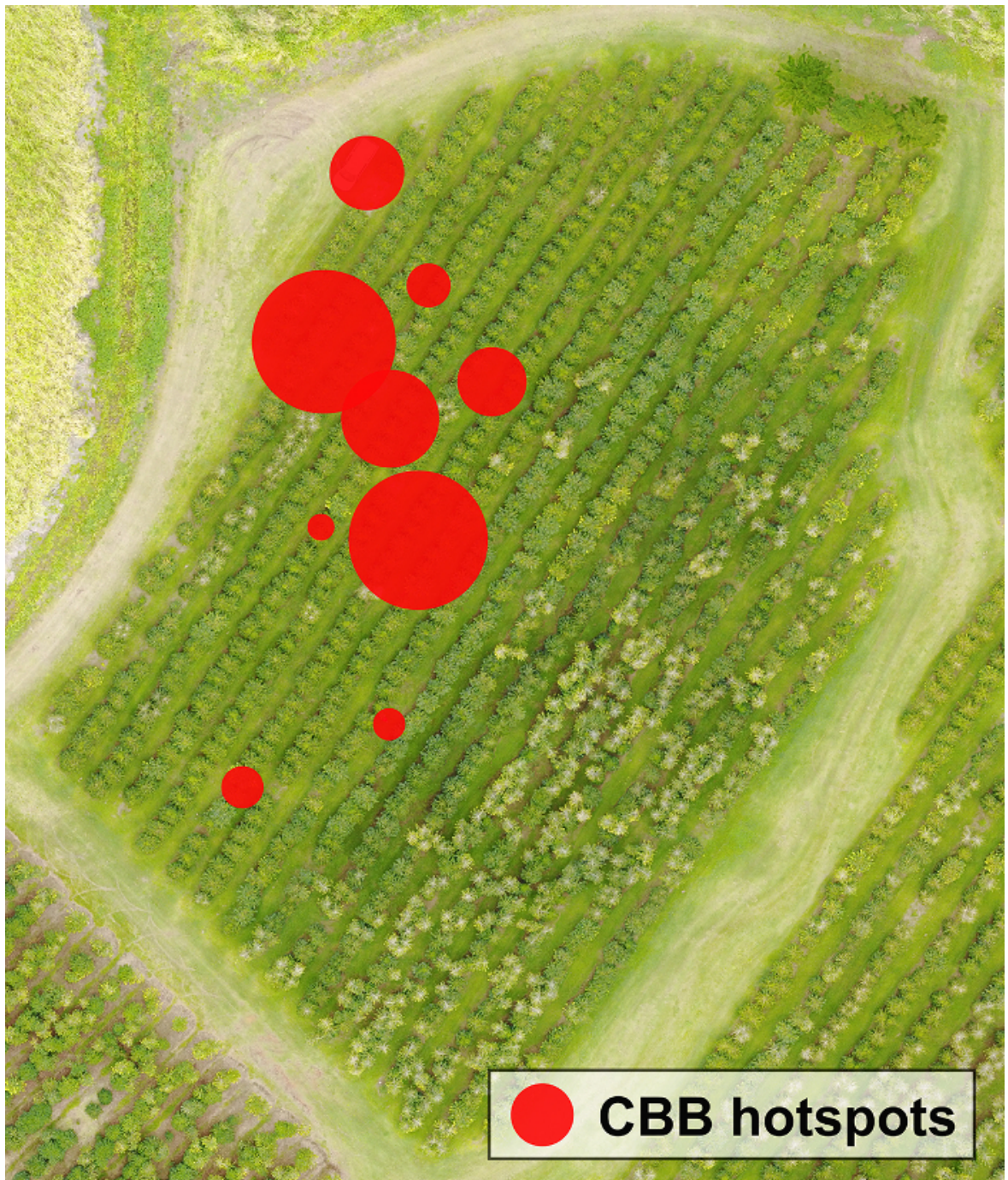

Figure 3. CBB infestation hotspots. This map of a sample coffee farm shows CBB infestation hotspots observed during a monitoring survey on June 14, 2017. The size of each red circle is proportional to the number of green infested berries on a sampled branch. In this sample farm, a total of 25 branches were sampled, and a range of 0 - 36 infested green berries was observed per branch. Please click here to view a larger version of this figure. 


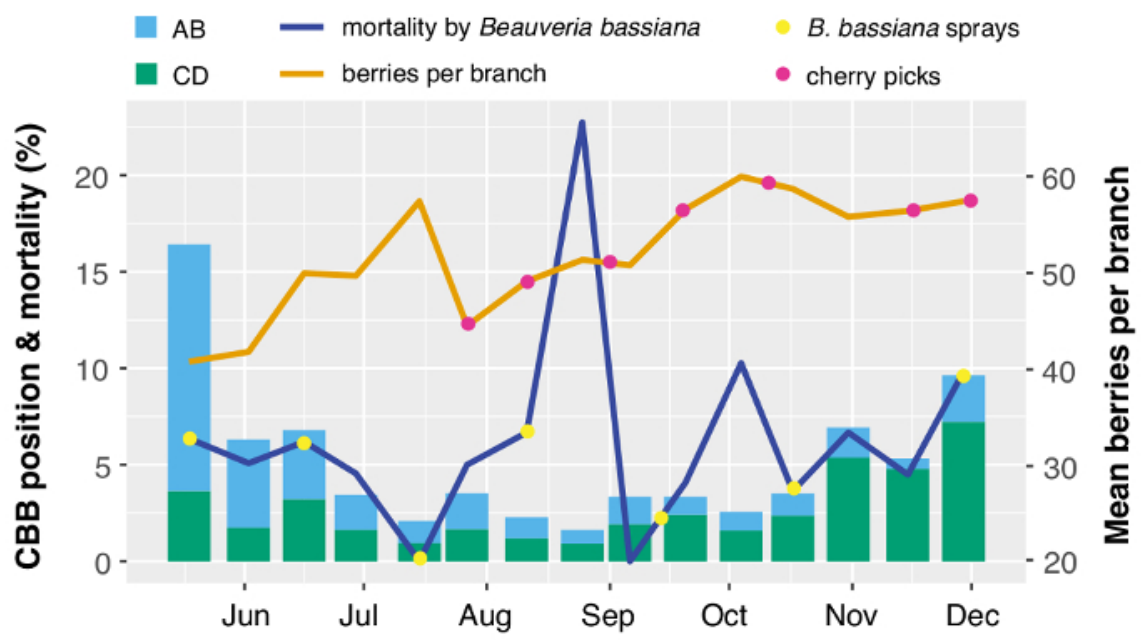

Figure 4. A comprehensive view of CBB infestation in a sample coffee farm. The position of CBB in dissected green berries is defined as $A B$ (the female has initiated penetration into the berry but has not reached the endosperm) or $C D$ (the female has entered the endosperm). Mortality of CBB (via the $B$. bassiana fungus), coffee plant phenology (the mean number of berries per branch), and farm management practices (B. bassiana sprays and cherry picks) are also displayed for the 2016 coffee-growing season. Please click here to view a larger version of this figure.

\section{Discussion}

The monitoring protocol described here can serve as an essential part of research on CBB and control strategies against this invasive coffee pest. We have put this monitoring protocol into practice over the 2016 and 2017 coffee growing seasons on Hawaii Island in an effort to optimize every step of the process outlined in this article and the accompanying video. By doing this, we have ensured that important aspects of CBB population dynamics have been monitored and quantified, that the most effective low-cost materials have been determined for each step of the protocol, and that the data collected on CBB movement, infestation, mortality, coffee plant phenology, weather and farm management can be used to inform and improve current control strategies.

There are a number of critical steps in this protocol that must be followed to ensure optimum results. First, funnel traps must be set up at a uniform height and positioned between trees. This will ensure that the attractant is sufficiently diffused through the air, and that beetles can access the trap from all directions. Second, it is necessary to use sieves with the same mesh size (coarse-mesh sieve $\approx 1.5 \mathrm{~mm}$, and fine-mesh sieve $\approx 1.0 \mathrm{~mm}$ ) throughout the duration of monitoring to ensure consistent results for volumetric estimates of CBB. Third, the proportion of CBB versus other beetles in each trap can vary considerably among traps and over the growing season, and it is therefore necessary to estimate these proportions to minimize noise in trap count data. Fourth, infested berries must be stored in a cooler on ice until they can be transported to the lab, after which berries should be stored at $14{ }^{\circ} \mathrm{C}$ until dissection. Storage in a humid environment will result in CBB emergence from the berries $^{20}$. Lastly, dissections must be conducted within $1-3$ days of collection to ensure maximum survivorship of CBB. Mortality of CBB may occur if berries are stored at cold temperatures for prolonged periods.

Additional steps may be required for research initiatives that are not included here (e.g., monitoring CBB predator abundance). Modifications may also be made to this protocol if time, resources, and/or equipment are limiting factors. The trap attractant comprised of 3:1 methanol:ethanol may be changed to a 1:1 methanol:ethanol solution with comparable results ${ }^{21}$. Soapy water may also be substituted for propylene glycol as a kill solution in traps ${ }^{22}$. For estimates of large numbers of CBB (e.g., more than several hundred per trap), mass-based estimates of CBB may be substituted in place of volumetric estimates. For example, the average dry weight of a single CBB may be determined using a highresolution scale. CBB collected in $70 \%$ ethanol may then be dried in an oven, and weighed to estimate the number of CBB per trap. A modified volumetric estimate can also be made by putting all the CBB from a trap into a graduated cylinder along with the kill solution, and allowing the contents to settle to the bottom ${ }^{22}$. Once settled, the volume of the cylinder filled by CBB may be noted, and the conversion factor for $1 \mathrm{~mL}$ may be determined to estimate the total number of CBB caught per trap. Lastly, coffee growers that have an intimate knowledge of their farms and are using this monitoring protocol to estimate CBB infestation and movement may wish to omit steps that involve documenting phenology and counting the number of raisins on branches.

Two potential limitations of this protocol are worth mentioning here. First, sampling of branches at chest height does not capture infestation in the early-flowering crop that may start higher in the tree canopy. However, the observations suggest that this early-flowering crop accounts for a very small percentage of the overall yield in coffee farms in Hawaii. Second, our protocol only accounts for infestation in green berries, and thus may not accurately capture estimates of berry damage when the number of color break and ripe berries is high (September - December in Hawaii).

The CBB monitoring protocol presented here has several distinct advantages over other monitoring protocols that are currently in use. First, the systematic random sampling design allows for more even sampling relative to sampling done in a zig-zag pattern. This sampling design allows for better estimates of berry damage throughout a given field, and increases the potential to detect hotspots. Second, the inclusion of elements in the monitoring protocol that are essential to coffee agroecosystems (e.g., phenology, weather variables, and management practices) will improve our understanding of the dynamics between invasive insect pests, their host plants, and various environmental factors. Third, the use of a mobile electronic data collection application during field surveys permits real-time data to be quickly and efficiently entered and organized into a database, and can also be related to other automated coffee monitoring methods such as detection via remote sensing ${ }^{23}$. Another important benefit of this method of data collection is that detailed infestation reports may be generated with ease, allowing timely 
management recommendations to be relayed to growers. Lastly, the real-time data collected on CBB biology, coffee plant phenology, weather, and management can be incorporated into the development of predictive models that can be used to customize management plans for a particular coffee growing location.

\section{Disclosures}

We have no conflicts of interest to report.

\section{Acknowledgements}

We are grateful to Forest Bremer for providing drone imagery of coffee farms, as well as assistance with GIS methods. We thank Thomas Mangine, Matthew Mueller, Lindsey Hamilton, Shannon Wilson, Briana McCarthy and Mehana Sabado-Halpern for assistance with film production, and two anonymous reviewers for comments on an earlier draft. This work was funded by USDA-ARS. Opinions, findings, conclusions or recommendations expressed in this publication are those of the authors and do not necessarily reflect the views of the USDA. USDA is an equal opportunity provider and employer.

\section{References}

1. Jaramillo, J., Borgemeister, C., Baker, P. Coffee berry borer Hypothenemus hampei (Coleoptera: Curculionidae): searching for sustainable control strategies. Bull. Entomol. Res. 96, 223-233. (2006).

2. Vega, F.E., Infante, F., Johnson, A.J. The genus Hypothenemus, with emphasis on $H$. hampei, coffee berry borer. In: Bark beetles, biology and ecology of native and invasive species. First ed.; Vega, F.E., Hofstetter, R.W. (Eds.); Elsevier: London, UK. Chapter 11, pp. 427-494. (2015).

3. ISO. International Standard ISO 10470. Green coffee -Defect reference chart. 15 pp. (2004).

4. Wegbe, K., Cilias, C., Decazy, B., Alauzet, C., Dufour, B. Estimation of production losses caused by the coffee berry borer (Coleoptera: Scolytidae) and calculation of an economic damage threshold in Togolese coffee plots. J. Econ. Entomol. 96, 1473-1478. (2003).

5. Burbano, E., Wright, M., Bright, D.E., Vega, F.E. New record for the coffee berry borer, Hypothenemus hampei, in Hawaii. J. Insect Sci. 11 (1), 117. (2011)

6. Kinro, G. A Cup of Aloha: The Kona Coffee Epic., University of Hawaii Press. (2003).

7. Teuber, R. Geographical indications of origin as a tool of product differentiation: The case of coffee. J. Int. Food Agribus. Mark. 22 (3-4), 277-298. (2010).

8. Leung, P.S., Kawabata, A.M., Nakamoto, S.T. Estimated economy-wide impact of CBB for the crop years 2011/12 and 2012/13. Brief report at request of Hawaii Congressional Delegation. 2 pp. (2014).

9. Baker, P.S., Jackson, J.A.F., Murphy, S.T. Natural Enemies, natural allies. Project completion report of the integrated management of coffee berry borer project, CFC/ICO/02 (1998-2002). The commodities press. CABI commodities, Egham UK and Cenicafé, Chinchiná, Colombia. (2002).

10. Brun, L.O., Marcillaud, C., Gaudichon, V., Suckling, D.M. Endosulfan resistance in Hypothenemus hampei (Coleoptera: Scolytidae) in New Caledonia. J. Econ. Entomol. 82, 1311-1316. (1989).

11. Vega, F.E., Infante, F., Castillo, A., Jaramillo, J. The coffee berry borer, Hypothenemus hampei (Ferrari) (Coleoptera: Curculionidae): a short review, with recent findings and future research directions. Terr. Arthropod Rev. 2, 129-147. (2009).

12. Aristizábal, L.F., Johnson, M., Shriner, S., Hollingsworth, R., Manoukis, N.C., Myers, R., Bayman, P., Arthurs, S.P. Integrated pest management of coffee berry borer in Hawaii and Puerto Rico: Current status and prospects. Insects. 8, 123. (2017).

13. Bustillo, A.E., Cardenas, M.R., Villalba, D., Orozco, J., Benavides, M.P., Posada, F.J. Manejo integrado de la broca del café Hypothenemus hampei. (Ferrari) en Colombia. Cenicafé, Chinchiná, Colombia. 134 pp. (1998).

14. Kawabata, A.M., Nakamoto, S.T., Curtiss, R.T. Recommendations for Coffee Berry Borer Integrated Pest Management in Hawai'i 2016. Insect Pests. IP-41. (2017).

15. Aristizábal, L.F., Jiménez, M., Bustillo, A.E., Trujillo, H.I., Arthurs, S.P. Monitoring coffee berry borer, Hypothenemus hampei (Coleoptera: Curculionidae), populations with alcohol baited funnel traps in coffee farms in Colombia. Fla. Entomol. 98 (1), 381-383. (2015).

16. Messing, R.H. The coffee berry borer (Hypothenemus hampei) invades Hawaii: Preliminary investigations on trap responses and alternate hosts. Insects . 3 (1), 640-652. (2012).

17. Arcila-Pulgarín, J., Buhr, L., Bleiholder, H., Hack, H., Meier, U., Wicke, H. Application of the extended BBCH scale for the description of the growth stages of coffee (Coffea spp.). Ann. Appl. Biol. 141 (1), 19-27. (2002).

18. Mathieu, F., Brun, L.O., Frérot, B. Factors related with native host abandonment by the Coffee Berry Borer Hypothenemus hampei (Ferrari) (Coleoptera: Scolytidae). J. Appl. Entomol. 121, 175-180. (1997).

19. Pereira, A.E., Vilela, E.F., Tinoco, R.S., de Lima, J.O.G., Fantine, A.K., Morais, E.G.F., Franca, C.F.M. Correlation between numbers captured and infestation levels of the Coffee Berry-borer, Hypothenemus hampei: A preliminary basis for an action threshold using baited traps. Int. J. Pest. Manage. 58 (2), 183-190. (2012).

20. Baker, P.S., Ley, C. Balbuena, R. Barrera, J.F. Factors affecting the emergence of Hypothenemus hampei (Coleoptera: Scolytidae) from coffee berries. Bull. Entomol. Res. 82, 145-150. (1992).

21. Dufour, B.P., Frérot, B. Optimization of coffee berry borer, Hypothenemus hampei Ferrari (Col., Scolytidae), mass trapping with an attractant mixture. J. Appl. Entomol. 132, 591-600. (2008).

22. Aristizábal, L.F., Shriner, S., Hollingsworth, R., Arthurs, S. Flight activity and field infestation relationships for coffee berry borer in commercial coffee plantations in Kona and Ka'u districts, Hawaii. J. Econ. Entomol. 110 (6), 2421-2427. (2017).

23. Gaertner, J., Genovese, V.B., Potter, C. Sewake, K., Manoukis, N.C. Vegetation classification of Coffea on Hawaii Island using Worldview-2 satellite imagery. J. App. Remote Sensing. 11, 046005. (2017). 